\title{
Technical note: Sampling and processing of mesocosm sediment trap material for quantitative biogeochemical analysis
}

\author{
Tim Boxhammer, Lennart T. Bach, Jan Czerny, and Ulf Riebesell \\ GEOMAR Helmholtz Centre for Ocean Research Kiel, Düsternbrooker Weg 20, 24105 Kiel, Germany \\ Correspondence to: Tim Boxhammer (tboxhammer@geomar.de)
}

Received: 28 October 2015 - Published in Biogeosciences Discuss.: 23 November 2015

Revised: 6 April 2016 - Accepted: 26 April 2016 - Published: 13 May 2016

\begin{abstract}
Sediment traps are the most common tool to investigate vertical particle flux in the marine realm. However, the spatial and temporal decoupling between particle formation in the surface ocean and particle collection in sediment traps at depth often handicaps reconciliation of production and sedimentation even within the euphotic zone. Pelagic mesocosms are restricted to the surface ocean, but have the advantage of being closed systems and are therefore ideally suited to studying how processes in natural plankton communities influence particle formation and settling in the ocean's surface. We therefore developed a protocol for efficient sample recovery and processing of quantitatively collected pelagic mesocosm sediment trap samples for biogeochemical analysis. Sedimented material was recovered by pumping it under gentle vacuum through a silicon tube to the sea surface. The particulate matter of these samples was subsequently separated from bulk seawater by passive settling, centrifugation or flocculation with ferric chloride, and we discuss the advantages and efficiencies of each approach. After concentration, samples were freeze-dried and ground with an easy to adapt procedure using standard lab equipment. Grain size of the finely ground samples ranged from fine to coarse silt $(2-63 \mu \mathrm{m})$, which guarantees homogeneity for representative subsampling, a widespread problem in sediment trap research. Subsamples of the ground material were perfectly suitable for a variety of biogeochemical measurements, and even at very low particle fluxes we were able to get a detailed insight into various parameters characterizing the sinking particles. The methods and recommendations described here are a key improvement for sediment trap applications in mesocosms, as they facilitate the processing of large amounts of samples and allow for high-quality biogeochemical flux data.
\end{abstract}

\section{Introduction}

Sediment traps of various designs have been the most common tool to study vertical particle flux in the oceans since the middle of the last century (Bloesch and Burns, 1980). During this period, the impact of anthropogenic pollution and climate change on marine biogeochemical cycles has grown steadily (Doney, 2010). Pelagic mesocosm systems enclose natural plankton communities in a controlled environment (Lalli, 1990; Riebesell et al., 2011) and allow us to investigate how changing environmental factors influence elemental cycling in the ocean's surface. The closed nature of these systems makes them particularly useful to investigate plankton community processes that quantitatively and qualitatively determine particle formation and settling. Cylindrical or funnel-shaped particle traps were suspended inside various pelagic mesocosm designs (Schulz et al., 2008; Svensen et al., 2001; Vadstein et al., 2012; von Bröckel, 1982). Covering only a small section of the mesocosm's diameter, they were prone to potential collection bias also well-known from oceanic particle traps, in particular in the upper ocean (Buesseler, 1991).

To study vertical particle flux in mesocosms it is essential to achieve the collection of all particles settling to the bottom. This not only improves the measurement accuracy but also drains the material from the pelagic system, as is the case in a naturally stratified water body. Different pelagic mesocosm designs like the Controlled Ecosystem Enclosures (CEE; Menzel and Case, 1977), the "large clean mesocosms" (Guieu et al., 2010), or the Kiel Off-Shore Mesocosms for future Ocean Simulations (KOSMOS; Riebesell et al., 2013) achieved the quantitative collection of settling particles through the cone-shaped bottom of the columnar enclosures. Two different techniques were generally used to sam- 
ple collected material of these sediment traps: (1) replaceable collection cups or polyethylene bottles, regularly exchanged by divers (Gamble et al., 1977; Guieu et al., 2010); (2) an extraction tube reaching down to the particle collector (Jinping et al., 1992; Menzel and Case, 1977; Riebesell et al., 2013).

The key difficulty of sediment trap applications in pelagic mesocosms is the sample processing after recovery. Depending on the setup (number of enclosures, trap design, sampling frequency, experiment duration), samples are high in number, relatively large in volume (up to several litres), and can reach extremely high particle densities during aggregation events.

In the past the collected material was usually only partly characterized to answer specific questions (e.g. Harrison and Davies, 1977; Huasheng et al., 1992; Olsen et al., 2007), while the full potential of the samples remained unexplored and the methodology of sample processing was commonly described in little detail. To fill this gap and to facilitate a broader biogeochemical analysis of the collected material, we refined methods for efficient sampling, particle concentrating, and processing of quantitatively collected mesocosm sediment trap samples. Our primary objective was the development of an efficient and easy to adopt protocol, which enables a comprehensive and accurate characterization of the vertical particle flux within pelagic mesocosms. The methods described in this paper were developed and applied during KOSMOS studies from 2010 until spring 2014 covering five different marine ecosystems at diverse stages in the succession of the enclosed plankton communities.

\section{Protocol for sampling and processing}

\subsection{Sampling strategy}

The sediment trap design of KOSMOS used since 2011 consists of a flexible thermoplastic polyurethane (TPU) funnel of $2 \mathrm{~m}$ in diameter, connected to the cylindrical mesocosm bag by a silicon-rubber-sealed glass fibre flange (Fig. 1a). A detailed description of the KOSMOS setup and maintenance requirements such as wall cleaning can be found in Riebesell et al. (2013). Settling particles are quantitatively collected on the $7 \mathrm{~m}^{2}$ funnel surface, where they slide down at a $63^{\circ}$ angle into the collecting cylinder, which has a volume of 3.1 L (Fig. 1b). A silicon tube of $1 \mathrm{~cm}$ inner diameter reaches down to the collecting cylinder outside of the mesocosm bag (Fig. 1a). A hose connector links the silicon tube to the conical bottom end of the collector, while a wire helix hose coating the first $1.5 \mathrm{~m}$ prevents currentrelated bending of the tube (Fig. 1b). The silicon tube itself is only connected to the bottom of the mesocosm and fixed to the floating frame above the sea surface to avoid any kinks (Fig. 1a). To empty the collecting cylinders, we connected $5 \mathrm{~L}$ Schott Duran ${ }^{\circledR}$ glass bottles via a Plexiglas ${ }^{\circledR}$ pipe to the silicon tubes attached to the floating mesocosm frames (Fig. 1b; Boxhammer et al., 2015). A slight vacuum
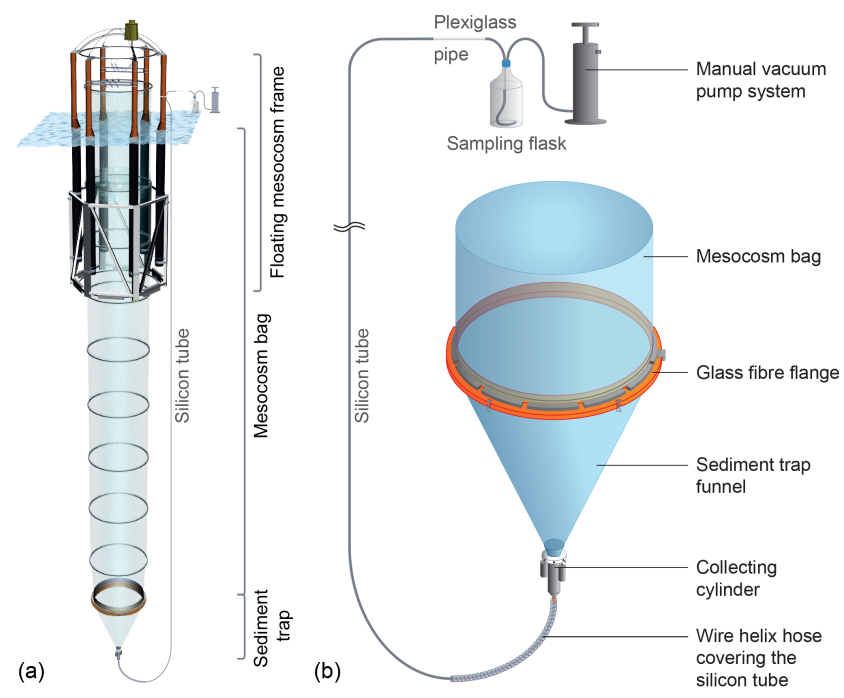

Figure 1. Panel (a): technical drawing of the KOSMOS flotation frame with unfolded TPU enclosure bag and attached funnel-shaped sediment trap. Panel (b): a silicon tube connects the collecting cylinder at the tip of the sediment trap with a $5 \mathrm{~L}$ sampling flask. A wirereinforced hose prevents current-related bending of the first $1.5 \mathrm{~m}$. Particles can be easily detected in the Plexiglass ${ }^{\circledR}$ pipe linking the silicon tube with the sampling flask.

of $\sim 300$ mbar was built up in the glass bottles by means of a manual kite surf pump to cause gentle suction of the water inside the silicon tubes (step 1 in Fig. 2). When first particles appeared in the Plexiglas ${ }^{\circledR}$ pipe, the sampling process was briefly interrupted and seawater in the bottles was screened for particles and only discarded if clear. The dense particle suspensions originating from the collecting cylinders were then vacuum-pumped into the sampling flasks until no more particles were passing through the Plexiglas ${ }^{\circledR}$ pipe in a sampled extra volume of about 0.5 L (Boxhammer et al., 2015).

Subsamples of sediment trap material for measurements such as zooplankton contribution (Niehoff et al., 2013), particle sinking velocity (Bach et al., 2012) or respiration rates of particle-colonizing bacteria were taken with a pipette after sample collection but prior to the processing of the bulk sample for biogeochemical analysis. For this the particle suspension $(\sim 1-4 \mathrm{~L})$ was gently mixed and subsample volumes withdrawn immediately before resuspended particles were able to settle down. The total volume of all subsamples should be kept low (ideally below 5\%) in order to limit the subsampling bias on the remaining sample that is processed for quantitative biogeochemical analysis. We occasionally noticed a patchy distribution of particles within the sampling bottles despite the mixing, but we consider this subsampling bias to be rather small because the subsample volume was usually large enough to tolerate a certain degree of sample heterogeneity. Quantities of the main sample and all subsamples were gravimetrically determined with an accuracy of $0.1 \mathrm{~g}$ for individual share calculations. 


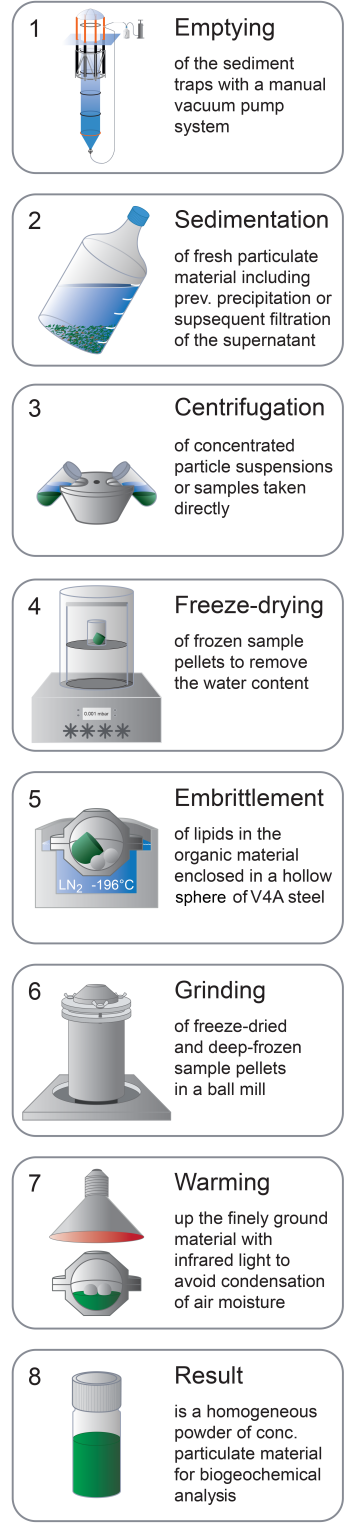

Figure 2. Protocol of mesocosm sediment trap sampling (1), particle concentration (2-3), freeze-drying (4), and grinding (5-8) to convert heterogeneous sediment trap samples into homogeneous powder for biogeochemical analysis.

\subsection{Separating particles from bulk seawater}

Particulate material recovered from the mesocosm sediment traps and transferred into sampling flasks needs to be separated from bulk seawater collected during the sampling procedure. In this section we describe three different methods for separating particles from bulk seawater, as this was the most critical and time-intense step in the sampling procedure.

The particle concentration efficiency (\%) of the three methods (Sects. 2.2.1-2.2.3) was determined as the percentage of total particulate carbon (TPC) concentrated in the pro- cessed samples in relation to the sum of concentrated and residual TPC in the remaining bulk water. Residual TPC in the bulk water was determined from subsamples that were filtered on combusted GF/F filters (Whatman; $0.7 \mu \mathrm{m}$ pore size, $\left.450^{\circ} \mathrm{C}, 6 \mathrm{~h}\right)$ with a gentle vacuum $(<200 \mathrm{mbar})$ and stored in combusted glass petri dishes $\left(450^{\circ} \mathrm{C}, 6 \mathrm{~h}\right)$ at $-20^{\circ} \mathrm{C}$. Copepods, which could occasionally be found in the liquid, were carefully removed from the filters right after filtration. The filters were oven-dried at $60^{\circ} \mathrm{C}$ over night, packed into tin foil, and stored in a desiccator until analysis. Combusted GF/F filters without filtered supernatant were included as blanks and measured alongside with the sample filters. The carbon and nitrogen content of the concentrated and subsequently dried and ground bulk material (processing procedure described in Sects. 2.3 and 2.4) was analysed from subsamples of $2 \pm 0.25 \mathrm{mg}$ in tin capsules $(5 \times 9 \mathrm{~mm}$, Hekatech). For this, subsamples were directly transferred into the tin capsules and weight was determined on a microbalance (M2P, Satorius) with an accuracy of $0.001 \mathrm{mg}$. All samples were measured with an elemental analyser (Euro EA-CN, Hekatech), which was calibrated with acetanilide $\left(\mathrm{C}_{8} \mathrm{H}_{9} \mathrm{NO}\right)$ and soil standard (Hekatech, catalogue no. HE33860101) prior to each measurement run.

\subsubsection{Separating particles from bulk seawater by passive settling}

Particles were allowed to settle for $2 \mathrm{~h}$ in $5 \mathrm{~L}$ glass bottles in darkness at in situ water temperature before separating the supernatant liquid. After this sedimentation period the supernatant was removed and transferred into separate vacuum bottles by means of a $10 \mathrm{~mL}$ pipette connected to a vacuum pump (Czerny et al., 2013; Gamble et al., 1977). We found the removal of the supernatant to be most efficient when glass bottles were stored at a $60^{\circ}$ angle so that particles could accumulate at the bottom edge of the bottles (step 2 in Fig. 2). The dense particle suspension at the bottom of the glass bottles was concentrated in $110 \mathrm{~mL}$ tubes by centrifugation for $10 \mathrm{~min}$ at $5039 \times g(3 \mathrm{~K} 12$ centrifuge, Sigma) to form compact sediment pellets (step 3 in Fig. 2). These pellets were then frozen at $-30^{\circ} \mathrm{C}$. A cable tie with its tip bent at a $90^{\circ}$ angle was stuck into each sample before freezing in order to enable easy recovery of the material from the centrifugation tubes. The frozen samples were transferred to plastic screw cap jars $(40-80 \mathrm{~mL})$ for preservation and storage in the dark at $-30^{\circ} \mathrm{C}$ before freeze-drying (Sect. 2.3).

Separating particulate material from the liquid by passive gravitational settling resulted in a median concentration efficiency of $92.9 \%$. The relatively wide range of scores (99.3$86.8 \%$ ) reflects a nonideal reproducibility of this particle concentration method (Fig. 3, green). The applied sedimentation period of $2 \mathrm{~h}$ was occasionally not long enough for small or low-density particles to settle. To increase the concentration efficiency of passive settling, longer sedimentation periods of up to $48 \mathrm{~h}$, e.g. for single plankton cells would be 


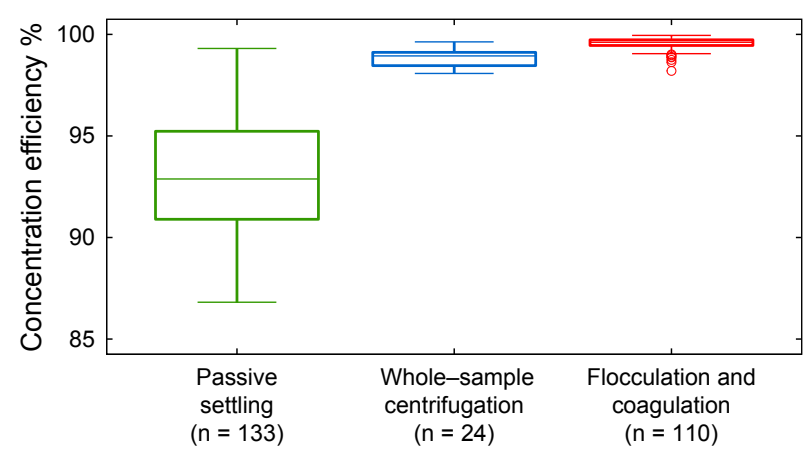

Figure 3. Box plot of the concentration efficiency (\%) of three different methods for particle concentration of mesocosm sediment trap samples. Concentration of particles by passive settling (green) is compared with gravitational deposition of particulates by wholesample centrifugation (blue). The third option of flocculation and coagulation with $\mathrm{FeCl}_{3}$ for enhanced particle settling is presented in red. Concentration efficiency is defined as the percentage of TPC concentrated in the processed sediment trap samples in relation to the particulate carbon in the originally sampled suspensions (sum of concentrated and residual TPC in the bulk water). Outliers (circles) are defined as any data points below $1.5 \times \mathrm{IQR}$ (interquartile range) of the first quartile hinge or above $1.5 \times \mathrm{IQR}$ of the third quartile hinge.

required. However, this is not practical at high sampling frequencies for a set of several mesocosms and would require poisoning of the samples to inhibit microbial degradation of organic matter.

\subsubsection{Separating particles from bulk seawater by whole-sample centrifugation}

Centrifuging the entire sample volume, which is usually between 1 and $4 \mathrm{~L}$, can considerably enhance gravitational separation of particles from bulk seawater. This procedure requires a large-volume centrifuge that is not necessarily standard lab equipment and difficult to take out into the field due to its high weight. For this approach we transferred particle suspensions originating from the sediment traps directly from the $5 \mathrm{~L}$ sampling flasks into $800 \mathrm{~mL}$ centrifuge beakers. The separation of particulate material was achieved within $10 \mathrm{~min}$ at $5236 \times g$ using a 6-16KS centrifuge (Sigma), followed by slow deceleration to avoid resuspension of particles (step 3 in Fig. 2). The supernatant was then carefully decanted and collected for filtration, while the sample pellets were transferred into $110 \mathrm{~mL}$ centrifuge tubes. This procedure was repeated until the $5 \mathrm{~L}$ sampling flasks were emptied. In a second step of centrifugation for $10 \mathrm{~min}$ at $5039 \times \mathrm{g}$ in the small tubes (3K12, Sigma) samples were compressed into compact sediment pellets which can be frozen and stored in plastic screw cap jars as described in Sect. 2.2.1.

Whole-sample centrifugation resulted in a high concentration efficiency of particles with a median of $98.9 \%$ and a low variability (98.1-99.6\%), indicating the high reproducibility of this method (Fig. 3, blue).

\subsubsection{Concentrating samples by flocculation and coagulation of particles}

Ferric chloride $\left(\mathrm{FeCl}_{3}\right)$ is well known as a flocculant and coagulant in sewage treatment (Amokrane et al., 1997; Renou et al., 2008) but can also be used for concentrating marine viruses (John et al., 2011) or microalgae (Knuckey et al., 2006; Sukenik et al., 1988). The iron ions form a series of metal hydrolysis species aggregating to tridimensional polymeric structures (sweeping flock formation) and enhance the adsorption characteristics of colloidal compounds by reducing or neutralizing their electrostatic charges (coagulation). Best precipitation results at a salinity of 29.6 were obtained by the addition of $300 \mu \mathrm{L}$ of $2.4 \mathrm{M} \mathrm{FeCl}_{3}$ solution per litre of well-stirred particle suspension, resulting in a very clear supernatant. The disadvantage of particle precipitation with $\mathrm{FeCl}_{3}$, however, is that $\mathrm{FeCl}_{3}$ is a fairly strong Lewis acid and therefore reduces the $\mathrm{pH}$ upon addition to a seawater sample. A pH decline in sediment trap samples needs to be avoided in order to prevent dissolution of collected calcium carbonate $\left(\mathrm{CaCO}_{3}\right)$.

To quantify the $\mathrm{FeCl}_{3}$-related $\mathrm{pH}$ reduction we added $\mathrm{FeCl}_{3}$ to (1) a seawater sample originating from mesocosms deployed in Gullmar Fjord (Sweden 2013) and (2) a seawater sample of the same origin in which we resuspended sediment trap material. This test was carried out in $500 \mathrm{~mL}$ beakers at $25^{\circ} \mathrm{C}$ using a stationary $\mathrm{pH}$ meter (NBS scale, 713, METROHM) to monitor changes in the seawater $\mathrm{pH}$ (Fig. 4). As expected, the addition of $150 \mu \mathrm{L} \mathrm{FeCl}_{3}(2.4 \mathrm{M})$ solution resulted in a distinct drop in seawater $\mathrm{pH}$ of about 3 units in the absence of particles (Fig. 4, blue, filled boxes) and 1.3 units in the presence of resuspended particles (Fig. 4, red, empty boxes). The $\mathrm{pH}$ decrease was compensated by stepwise titration with $3 \mathrm{M} \mathrm{NaOH}$, reaching the initial seawater $\mathrm{pH}$ after the addition of $\sim 330 \mu \mathrm{L} \mathrm{NaOH}$ both in the absence and the presence of particles. In both cases the calculated aragonite saturation state, representing the more soluble form of biogenic $\mathrm{CaCO}_{3}$, was well above $\Omega=1$ (Fig. 4, grey dashed line), as calculated with CO2SYS MS Excel Macro (Pierrot et al., 2006) at $25^{\circ} \mathrm{C}, 0 \mathrm{dbar}$, a salinity of 29.62 , and total alkalinity (TA) of 2206.1 (Bach et al., 2016) with constants of Mehrbach et al. (1973), refitted by Dickson and Millero (1987).

According to the test, $660 \mu \mathrm{L} \mathrm{NaOH}(3 \mathrm{M})$ were simultaneously added with $300 \mu \mathrm{L} \mathrm{FeCl}_{3}(2.4 \mathrm{M})$ to each litre of particle suspension to stabilize the sample $\mathrm{pH}$ and to achieve optimal particle precipitation (Supplement S1). The formation of dense and rapidly settling flocks allowed the separation of the supernatant and concentration of the deposit as described in Sect. 2.2.1 after only $1 \mathrm{~h}$ of sedimentation. Even though buffering the samples with $\mathrm{NaOH}$, we still observed shifts in seawater $\mathrm{pH}$. Delta $\mathrm{pH}(\Delta \mathrm{pH})$ was calculated from 


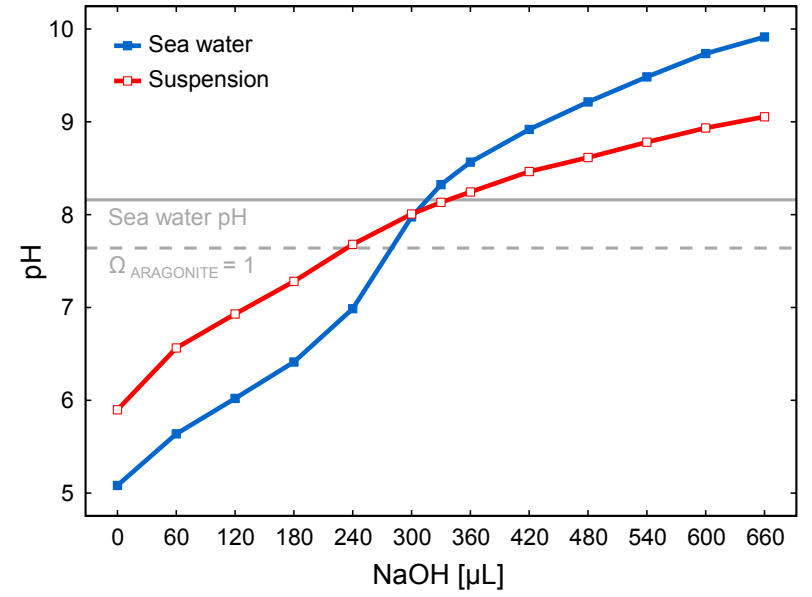

Figure 4. Titration of $500 \mathrm{~mL}$ sea water (blue, filled box and line) and $500 \mathrm{~mL}$ particle suspension (red, empty box and line) with $3 \mathrm{M} \mathrm{NaOH}$ after addition of $150 \mu \mathrm{L} 2.4 \mathrm{M} \mathrm{FeCl}_{3}$ solution. The grey solid line indicates the $\mathrm{pH}$ of seawater before any manipulation. $\mathrm{pH}$ (NBS scale) was measured at $25^{\circ} \mathrm{C}$ with a stationary $\mathrm{pH}$ meter $(713$, METROHM). Calculated aragonite saturation state of $\Omega=1$ is represented by the grey dashed line.

$50 \mathrm{pH}$ measurements before and after the addition of $\mathrm{FeCl}_{3}$ and $\mathrm{NaOH}$ to sediment trap samples (pH meter, $3310 \mathrm{WTW}$; InLab Routine Pt1000 electrode, Mettler Toledo). The resulting $\Delta \mathrm{pH}$ (Fig. 5) differed between individual samples of the same day as well as between sampling days over the 107 days of the experiment. A maximum spread of $0.46 \mathrm{pH}$ units was observed on day 63 , while the minimum difference of 0.15 units occurred on day 103 . We did not detect a trend towards a positive or negative shift in $\mathrm{pH}$ as the variation in the data led to an average $\Delta \mathrm{pH}$ of -0.01 . It is likely that differences in the amount and composition of particles in the samples led to the observed pattern. Aragonite and calcite saturation states of the samples after precipitation (Fig. 5) were calculated as described above using in situ storage temperature, $\mathrm{pH}$ measurements of the samples, and TA values from mesocosm water column measurements (Bach et al., 2016). Undersaturation of both carbonate species already occurred in several samples prior to $\mathrm{FeCl}_{3}$ addition as ocean acidification scenarios were established inside the mesocosm bags and $\mathrm{CO}_{2}$ released by biomass degradation likely further reduced seawater $\mathrm{pH}$. In fact the number of undersaturated samples after precipitation was reduced by two and six samples with respect to aragonite and calcite. This method can therefore also be used to eliminate undersaturation of $\mathrm{CaCO}_{3}$ in the samples as a consequence of $\mathrm{CO}_{2}$ released by microbial degradation of the collected organic matter.

The $\mathrm{FeCl}_{3}$ approach yielded the highest concentration efficiency among the three methods with a median of $99.6 \%$ and a narrow range of scores (98.2-99.9\%), indicating a remarkable reproducibility (Fig. 3, red). The outliers seen in the box plot are likely caused by extremely high amounts

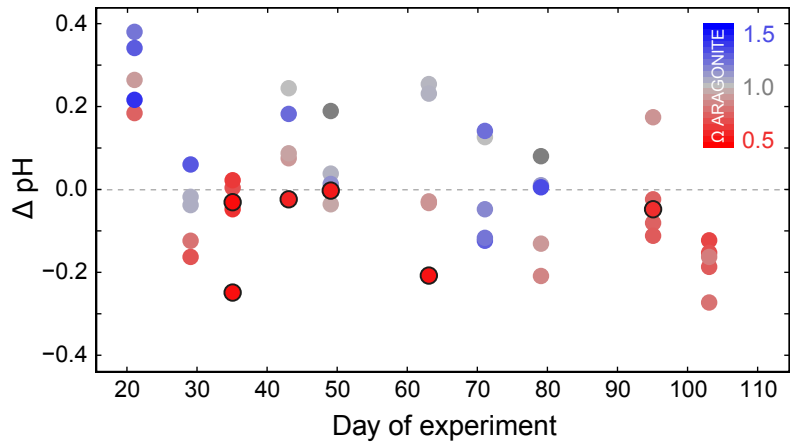

Figure 5. Delta $\mathrm{pH}$ of 50 sediment trap samples, calculated from $\mathrm{pH}$ measurements before and after addition of $\mathrm{FeCl}_{3}\left(300 \mu \mathrm{LL}^{-1}\right.$, $2.4 \mathrm{M})$ and $\mathrm{NaOH}\left(660 \mu \mathrm{LL}^{-1}, 3 \mathrm{M}\right)$ for precipitation of suspended particulate material. $\Omega_{\text {ARAGONITE }}$ after chemical treatment of the samples is indicated by a colour gradient from red to grey to blue, representing undersaturated, saturated, and oversaturated samples, respectively. $\Omega_{\text {CALCITE }}<1$ is indicated by black edging of the coloured data points.

of transparent exopolymer particles (TEP) in specific samples. We observed TEP in the supernatant of these samples in the form of strings (Alldredge et al., 1993) likely promoting buoyancy of attached particles (Azetsu-Scott and Passow, 2004) and thereby explaining the slightly decreased concentration efficiency in these samples.

\subsection{Freeze-drying samples}

The water content of the frozen samples was removed by freeze-drying for up to $72 \mathrm{~h}$ depending on pellet size (step 4 in Fig. 2). Lyophilization is preferable to drying the material in the oven for better preservation of phytoplankton pigments (McClymont et al., 2007) and a significant improvement of pigment extraction (Buffan-Dubau and Carman, 2000; van Leeuwe et al., 2006). Sedimentation rates within the mesocosms (expressed as collected dry weight per unit time) were gravimetrically determined and should be corrected for sea salt content. Residual sea salt can be estimated with the known loss of water during freeze-drying and known salinity of water in the respective samples. The alternative of removing sea salt before freeze-drying with ultra pure water has the downside of potential osmotic cell rupture and loss of intracellular compounds and should therefore be avoided.

\subsection{Grinding the desiccated material}

The desiccated sediment pellets were cryogenically ground into a fine powder of homogeneous composition to guarantee representative subsampling. We therefore developed a ball mill to grind sample sizes from 0.1 to $7.0 \mathrm{~g}$ dry weight. Hollow spheres with volumes ranging from 11.5 to $65.5 \mathrm{~mL}$ were cut out of blocks of stainless steel (V4A/1.4571). Each hollow sphere is divided into two hemispheres of exactly the 
Table 1. Depending on the dry weight of the freeze-dried sediment trap samples, different grinding sphere volumes and numbers of grinding balls $(10-20 \mathrm{~mm})$ are recommended to achieve optimal grinding results at a set run time of the ball mill (5 min). The optimal combination of the different factors was determined empirically to achieve a grain size smaller than $63 \mu \mathrm{m}$ and to minimize frictional heating of the samples.

\begin{tabular}{llll}
\hline $\begin{array}{l}\text { Sample } \\
\text { dry weight } \\
(\mathrm{g})\end{array}$ & $\begin{array}{l}\text { Hollow sphere } \\
\text { volume } \\
(\mathrm{mL})\end{array}$ & $\begin{array}{l}\text { No. of grinding } \\
\text { balls and size } \\
(\mathrm{mm})\end{array}$ & $\begin{array}{l}\text { Run time of } \\
\text { the ball mill } \\
(\mathrm{min})\end{array}$ \\
\hline$<1.5$ & 11.5 & $1 \times 10$ & 5 \\
$1.5-2.5$ & 24.4 & $1 \times 15+2 \times 10$ & 5 \\
$2.5-5.0$ & 47.7 & $2 \times 15+2 \times 10$ & 5 \\
$5.0-7.0$ & 65.5 & $1 \times 20$ & 5 \\
\hline
\end{tabular}

same shape and only connected by two guide pins and sealed by a metal sealing (Fig. S1 in Supplement). The size of the grinding sphere was selected according to the dry weight of the freeze-dried sediment pellets (Table 1). A set number and size of grinding balls (stainless steal, 1.3541) ranging from 10 to $20 \mathrm{~mm}$ in diameter is transferred into the hemisphere containing the sample pellet (Table 1). The second hemisphere is then put on top of the other so that the two hemispheres form a hollow sphere with the sample and the grinding balls locked inside. Sediment pellets heavier than $7.0 \mathrm{~g}$ have to be split up into multiple spheres and require homogenization after grinding. After loading the grinding spheres we cooled them down in liquid nitrogen (step 5 in Fig. 2) until the liquid stopped boiling $\left(-196^{\circ} \mathrm{C}\right)$. We observed that deep-freezing of the samples is essential for embrittlement of lipids in the organic matter and additionally protects phytoplankton pigments from frictional heating during the grinding process. The deep-frozen spheres $\left(\mathrm{ca} .-196^{\circ} \mathrm{C}\right)$ were clamped on a cell mill (Vibrogen VI 6, Edmund Bühler) and shaken at $75 \mathrm{~Hz}$ for 5 min (step 6 in Fig. 2), thereby grinding the material by impact and friction. Before opening the grinding spheres they needed to be warmed up to room temperature to avoid condensation of air moisture on the ground sample material. This was done by means of infrared light bulbs $(150 \mathrm{~W})$ installed at about $5 \mathrm{~cm}$ distance (step 7 in Fig. 2). The very finely ground samples were then recovered from the opened spheres with a spoon and transferred into gas tight glass vials to protect the powder from air moisture (step 8 in Fig. 2). Samples were stored in the dark at $-80^{\circ} \mathrm{C}$ to minimize pigment degradation. All handling of the samples during the grinding process was done over a mirror for complete recovery of the ground material.

We evaluated the homogeneity of finely ground sediment trap samples by five repetitive carbon and nitrogen measurements of samples collected during experiments in different ocean regions between 2010 and 2014 (Table 2). The reproducibility of the measurements was expressed by the coefficient of variation in percent $(\mathrm{CV} \%)$ reflecting the dispersion
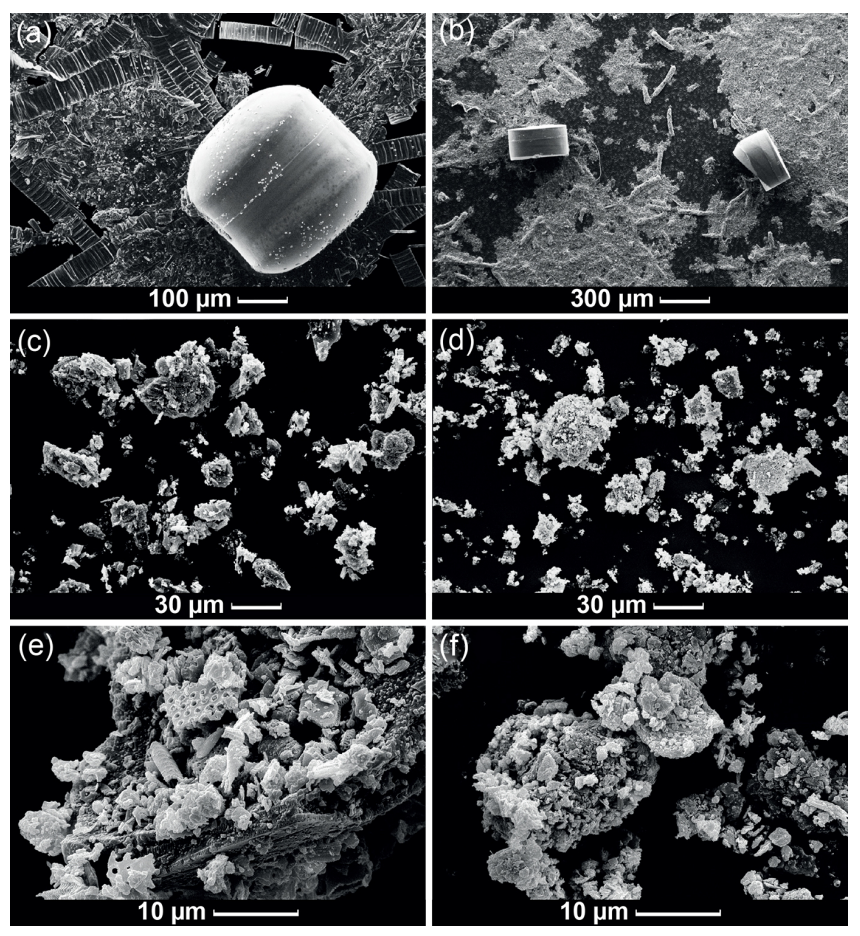

Figure 6. Scanning electron microscopy (SEM) photographs of two sediment trap samples before (a, b) and after grinding (c-f). Panels (c) and (d) represent the average grain size of the ground samples, while (e) and (f) reveal details visible at 2500-fold magnification.

of measurements relative to the mean:

$\mathrm{CV} \%=\frac{\mathrm{SD}}{\mathrm{MEAN}} \times 100$

The CV \% estimates demonstrated that carbon (CV \%: 0.15$0.99)$ and nitrogen (CV\%: 0.28-1.86) measurements of the ground samples were at least equally reproducible as measurements of the two calibration standards acetanilide and a soil standard with a CV\% of 0.34 and 4.17 for carbon and 0.97 and 1.55 for nitrogen, respectively (Table 2).

The homogeneity of ground samples is mainly determined by the grain size, which is therefore crucial for representative subsampling. Scanning electron microscopy (SEM) photographs of fresh sediment trap samples (Fig. 6a, b) show that the collected material consists of a heterogeneous mixture of all kind of debris particles, such as agglutinated diatom chains, faecal pellets, and macroscopic aggregates. None of these macroscopic structures were visible after the grinding procedure (Fig. 6c, d). Only at 2500-fold magnification did details such as pores of former diatom frustules become detectable in tiny fragments (Fig. 6e, f). Grain size, representing grinding quality, was in the range of fine to coarse silt (2-63 $\mu \mathrm{m}$, international scale), independently of the sample origin and primary composition (Fig. 6c, d). 
Table 2. Results from replicate carbon and nitrogen measurements of ground sediment trap material used to test its homogeneity. Powdered samples originating from different pelagic mesocosm experiments were tested and compared with commercially available standards commonly used for calibration of elemental analysers (soil standard (std), acetanilide standard (std)). Homogeneity is expressed by the coefficient of variation in percent (CV\%). Also presented are the number of measured aliquots, the amount of material analysed, average carbon content, calculated standard deviation (SD), and grain size derived from scanning electron microscopy. ND: grain size not determined.

\begin{tabular}{|c|c|c|c|c|c|c|c|c|c|}
\hline $\begin{array}{l}\text { Sample } \\
\text { origin }\end{array}$ & $\begin{array}{l}\text { Measured } \\
\text { aliquots } \\
\text { no. }\end{array}$ & $\begin{array}{l}\text { Aliquot } \\
\text { weight } \\
(\mathrm{mg})\end{array}$ & $\begin{array}{l}\text { Grain } \\
\text { size } \\
(\mu \mathrm{m})\end{array}$ & $\begin{array}{l}\text { Average } \\
\text { carbon } \\
\left(\mu \mathrm{mol} \mathrm{mg}{ }^{-1}\right)\end{array}$ & $\begin{array}{l}\text { SD } \\
\text { (carbon) }\end{array}$ & $\begin{array}{l}\text { CV \% } \\
\text { (carbon) }\end{array}$ & $\begin{array}{l}\text { Average } \\
\text { nitrogen } \\
(\mu \mathrm{mol} \mathrm{mg}-1)\end{array}$ & $\begin{array}{l}\text { SD } \\
\text { (nitrogen) }\end{array}$ & $\begin{array}{l}\text { CV \% } \\
\text { (nitrogen) }\end{array}$ \\
\hline $\begin{array}{l}\text { Soil std } \\
C=3.429 \%\end{array}$ & 5 & $4 \pm 0.25$ & ND & 2.83 & 0.12 & 4.17 & 0.16 & 0.00 & 1.55 \\
\hline $\begin{array}{l}\text { Acetanilide std } \\
C=71.089 \%\end{array}$ & 5 & $1 \pm 0.15$ & ND & 58.81 & 0.20 & 0.34 & 7.34 & 0.07 & 0.97 \\
\hline $\begin{array}{l}\text { Svalbard } 2010 \\
\text { No. SV106 }\end{array}$ & 5 & $2 \pm 0.25$ & ND & 22.74 & 0.12 & 0.51 & 3.77 & 0.01 & 0.39 \\
\hline $\begin{array}{l}\text { Norway } 2011 \\
\text { No. NO124 }\end{array}$ & 5 & $2 \pm 0.25$ & $\leq 63$ & 19.57 & 0.09 & 0.48 & 2.53 & 0.01 & 0.54 \\
\hline $\begin{array}{l}\text { Finland } 2012 \\
\text { No. FI114 }\end{array}$ & 5 & $2 \pm 0.25$ & $\leq 63$ & 22.53 & 0.03 & 0.15 & 3.58 & 0.01 & 0.28 \\
\hline $\begin{array}{l}\text { Sweden } 2013 \\
\text { No. SE502 }\end{array}$ & 5 & $2 \pm 0.25$ & $\leq 63$ & 29.03 & 0.23 & 0.80 & 1.65 & 0.03 & 1.86 \\
\hline $\begin{array}{l}\text { Gran Canaria } 2014 \\
\text { No. GC68 }\end{array}$ & 5 & $2 \pm 0.25$ & $\leq 63$ & 17.15 & 0.17 & 0.99 & 0.94 & 0.00 & 0.28 \\
\hline
\end{tabular}

\section{Conclusions and recommendations}

\subsection{Sediment trap design and sample recovery}

The quantitative collection of settling particles, as realized in several pelagic mesocosm designs (e.g. CEE, KOSMOS, Large Clean Mesocosms), combines the advantage of sampling all settling particles produced by the enclosed plankton community with the removal of settled organic matter from the bottom of the enclosures. Collecting all settling particles avoids the potential sampling bias of suspended particle traps in mesocosm enclosures and leads to more accurate particle flux rates. Removing the accumulating material prevents resuspension and non-quantified resupply of nutrients and other dissolved compounds released by degradation back into the water column.

We applied the vacuum sampling method to allow easy sample recovery at short time intervals and to keep the systems sealed for minimal disturbance of the enclosed water bodies. Opening of the sediment traps even for a very short time can lead to water exchange due to density gradients between the enclosed and the surrounding water. The vacuum sampling method is therefore ideal to keep the mesocosm enclosures completely sealed and thereby exclude the introduction of plankton seed populations and to allow for the proper budgeting of elements. Furthermore, the extraction of the collected material from the sea surface does not require diving activities. Only in case of a nonreversible blockage of the outlet of the collecting cylinder by artificial objects do divers need to open up the collecting cylinder at the top or the bottom.
Sediment traps of mesocosms can obviously not be poisoned to prevent organic matter degradation, raising the importance of frequent sampling. Sampling intervals of the traps should be kept short -2 days or less - to limit bacterialand zooplankton-mediated remineralization of the settled material and to avoid or minimize the time of possible carbonate undersaturation or anoxic conditions.

\subsection{Particle concentration}

Centrifuging the entire sample volume (Sect. 2.2.2) as well as precipitating particles with $\mathrm{FeCl}_{3}$ (Sect. 2.2.3) was shown to effectively concentrate sediment trap samples containing large amounts of bulk seawater without the need for separate analysis of the supernatant. In contrast, particle concentration by passive settling (Sect. 2.2.1) should be complemented by additional measurements of material remaining in the supernatant as mean concentration efficiency is much lower and more dependent on particle characteristics.

The simplest method to use in the field was centrifugation of the whole sample volume. We therefore recommend this method for sample volumes of up to $3 \mathrm{~L}$, as it avoids separate supernatant analysis or readjustment of the samples' $\mathrm{pH}$ and undesired enrichment with iron. Concentration of samples larger than $3 \mathrm{~L}$ can be accelerated by precipitation of particles with $\mathrm{FeCl}_{3}$ prior to centrifugation and is advisable during bloom and post-bloom events of high particle fluxes. If applied in the future, we strongly advise adjusting $\mathrm{pH}$ after $\mathrm{FeCl}_{3}$ addition with $\mathrm{NaOH}$ in each sample individually to ensure $\mathrm{CaCO}_{3}$ preservation. $\mathrm{FeCl}_{3}$ is also known to precipitate dissolved inorganic phosphate $\left(\mathrm{PO}_{4}^{3-}\right)$ (Jenkins et al., 1971), 
Table 3. List of parameters measured from ground sediment trap samples originating from KOSMOS experiments. The methods or instruments applied and the corresponding references with data sets and detailed descriptions of the methods are also provided.

\begin{tabular}{|c|c|c|}
\hline Parameter & Method or instrument & Corresponding publications \\
\hline Total carbon & Elemental analyser & $\begin{array}{l}\text { Czerny et al. (2013), } \\
\text { Paul et al. (2015b) }\end{array}$ \\
\hline Organic carbon & $\begin{array}{l}\text { Removal of inorganic carbon by } \\
\text { direct addition of hydrochloric } \\
\text { acid (Bisutti et al., 2004); } \\
\text { elemental analyser }\end{array}$ & Riebesell et al. (2016) \\
\hline Inorganic carbon & $\begin{array}{l}\text { Calculated from total and org. } \\
\text { carbon }\end{array}$ & Riebesell et al. (2016) \\
\hline Total nitrogen & Elemental analyser & $\begin{array}{l}\text { Czerny et al. (2013), } \\
\text { Paul et al. (2015b) }\end{array}$ \\
\hline Phosphorus & $\begin{array}{l}\text { Spectrophotometry } \\
\text { (Hansen and Koroleff, 1999) }\end{array}$ & $\begin{array}{l}\text { Czerny et al. (2013), } \\
\text { Paul et al. (2015b) }\end{array}$ \\
\hline Biogenic silica & $\begin{array}{l}\text { Spectrophotometry } \\
\text { (Hansen and Koroleff, 1999) }\end{array}$ & $\begin{array}{l}\text { Czerny et al. (2013), } \\
\text { Paul et al. (2015b) }\end{array}$ \\
\hline Isotopic tracers $\left({ }^{13} \mathrm{C},{ }^{15} \mathrm{~N}\right)$ & $\begin{array}{l}\text { Mass spectrometry, } \\
\text { elemental analyser }\end{array}$ & $\begin{array}{l}\text { de Kluijver et al. (2013), } \\
\text { Paul et al. (2015a) }\end{array}$ \\
\hline Phytoplankton pigments & $\begin{array}{l}\text { High-pressure liquid } \\
\text { chromatography }\end{array}$ & Paul et al. (2015a) \\
\hline
\end{tabular}

but the relative contribution of precipitated $\mathrm{PO}_{4}^{3-}$ to particulate phosphorus in the samples is likely to be negligible. The potential of iron to interfere with the spectrophotometric analysis of biogenic silica or particulate phosphorus leading to increased absorption at very high iron concentrations (Hansen and Koroleff, 1999) can not be confirmed based on our observations (author's unpublished data).

\subsection{Sample analyses}

Processing of the sediment trap material to a finely ground and homogeneous powder proved to be ideally suited for reproducible elemental composition analysis. So far we successfully measured the content of major bioactive elements such as total, organic, and inorganic carbon, nitrogen, phosphorus, and biogenic silica using standard methods for particulates in seawater (Table 3). Isotopic tracers such as ${ }^{13} \mathrm{C}$ and ${ }^{15} \mathrm{~N}$ added to the mesocosms as well as natural isotope signals were additionally measured in settled organic matter (de Kluijver et al., 2013; Paul et al., 2015a). Furthermore, phytoplankton pigments extracted from the ground samples were analysed revealing the contribution of key phytoplankton groups to settling particle formation (Paul et al., 2015a). As only a few milligram of material are needed for these analyses, the measurement of further parameters such as lithogenic material or amino acids should be tested in the future.

\subsection{Recommendations}

This section highlights the most important recommendations for improving particle collection in pelagic mesocosms along with sampling and processing of the collected material for biogeochemical analysis. The recommendations are as follows.

- Quantitative collection of settling particles with fullsize funnel traps leads to accurate flux measurements and minimizes the impact of organic matter degradation on the enclosed water columns.

- Vacuum sampling of the sediment traps via an extraction tube allows keeping the mesocosms sealed, excluding seawater and organism exchange.

- High sampling frequency limits organic matter degradation and potential carbonate undersaturation or anoxia in the traps.

- Separation of particles and bulk seawater in the samples is highly efficient when achieved by centrifugation or chemical precipitation with $\mathrm{FeCl}_{3}$.

- Freeze-drying the collected material is preferable to drying the samples in the oven to better preserve phytoplankton pigments.

- Grinding of the entire samples guarantees representative subsampling for biogeochemical analysis.

Following our successfully applied protocol (Fig. 2, Sect. 2) and the above recommendations will lead to accurate biogeochemical flux data of mesocosm sediment traps, irrespective of the magnitude of the particle flux.

The Supplement related to this article is available online at doi:10.5194/bg-13-2849-2016-supplement. 
Author contributions. U. Riebesell conceived the mesocosm experiments between 2010 and spring 2014. T. Boxhammer and J. Czerny developed the methods for sample acquisition and material processing. T. Boxhammer carried out the practical work, while the presented data were analysed by T. Boxhammer and L. T. Bach. $\mathrm{T}$. Boxhammer prepared the manuscript with contributions from all co-authors.

Acknowledgements. We thank the whole KOSMOS team for deployment and maintenance of the KOSMOS infrastructures during the five consecutive mesocosms studies between 2010 and spring 2014. In particular, we thank Andrea Ludwig and Sebastian Krug for coordinating the logistics and conducting CTD casts, Ylva Ericson and Leif Anderson for providing TA data, Allanah J. Paul for support with RStudio, Jan Taucher for supervision, Sebastian Meier from the Institute of Geology at the Kiel University for support regarding SEM analyses, Mario Deckelnick and Detlef Hoffmann for the development of the ball mill as well as Michael Sswat, Mathias Haunost, Hendrik Schultz, Saskia Audritz, Jana Meyer, Diana Gill, Kerstin Nachtigall, and Georgia Slatter for assistance during sampling, processing, and measurements. We are also grateful to the crews of M/V Esperanza, R/V Alkor (AL376, AL394, AL397, AL406, AL420), R/V Håkan Mosby (2011609), R/V Heincke (HE360), R/V Poseidon (POS463), and R/V Hesperides (29HE20140924) for transportation, deployment, and recovery of the mesocosms. This paper benefited from the constructive comments of two anonymous reviewers. The mesocosm studies were funded by the Federal Ministry of Education and Research (BMBF) in the framework of the coordinated projects BIOACID II (FKZ 03F06550) and SOPRAN II (FKZ 03F0611), as well as by the European Union in the framework of the FP7 EU projects MESOAQUA (grant agreement no. 228224) and EPOCA (grant agreement no. 211384).

Edited by: K. G. Schulz

\section{References}

Alldredge, A. L., Passow, U., and Logan, B. E.: The abundance and significance of a class of large, transparent organic particles in the ocean, Deep-Sea Res. Pt. I, 40, 1131-1140, 1993.

Amokrane, A., Comel, C., and Veron, J.: Landfill leachates pretreatment by coagulation-flocculation, Water Res., 31, 2775-2782, 1997.

Azetsu-Scott, K. and Passow, U.: Ascending marine particles: Significance of transparent exopolymer particles (TEP) in the upper ocean, Limnol. Oceanogr., 49, 741-748, 2004.

Bach, L. T., Riebesell, U., Sett, S., Febiri, S., Rzepka, P., and Schulz, K. G.: An approach for particle sinking velocity measurements in the 3-400 $\mu \mathrm{m}$ size range and considerations on the effect of temperature on sinking rates, Mar. Biol., 159, 1853-1864, 2012.

Bach, L. T., Taucher, J., Boxhammer, T., Ludwig, A., The Kristineberg Kosmos Consortium, Achterberg, E. P., AlgueróMuñiz, M., Anderson, L. G., Bellworthy, J., Büdenbender, J., Czerny, J., Ericson, Y., Esposito, M., Fischer, M., Haunost, M., Hellemann, D., Horn, H. G., Hornick, T., Meyer, J., Sswat, M.,
Zark, M., and Riebesell, U.: Influence of ocean acidification on a natural winter-to-summer plankton succession: First insights from a long-term mesocosm study draw attention to periods of low nutrient concentrations, in review, 2016.

Bisutti, I., Hilke, I., and Raessler, M.: Determination of total organic carbon - an overview of current methods, Trac-Trend. Anal. Chem., 23, 716-726, 2004.

Bloesch, J. and Burns, N. M.: A critical review of sedimentation trap technique, Schweiz, Z. Hydrol., 42, 15-55, 1980.

Boxhammer, T., Bach, L. T., Czerny, J., Nicolai, M., Posman, K., Sswat, M., and Riebesell, U.: Video of the sampling strategy to empty sediment traps of the "Kiel Off-Shore Mesocosms for future Ocean Simulations" (KOSMOS), 2015.

Buesseler, K. O.: Do upper-ocean sediment traps provide an accurate record of particle flux?, Nature, 353, 420-423, 1991.

Buffan-Dubau, E. and Carman, K. R.: Extraction of benthic microalgal pigments for HPLC analyses, Mar. Ecol.-Prog. Ser., 204, 293-297, 2000.

Czerny, J., Schulz, K. G., Boxhammer, T., Bellerby, R. G. J., Büdenbender, J., Engel, A., Krug, S. A., Ludwig, A., Nachtigall, K., Nondal, G., Niehoff, B., Silyakova, A., and Riebesell, U.: Implications of elevated $\mathrm{CO}_{2}$ on pelagic carbon fluxes in an Arctic mesocosm study - an elemental mass balance approach, Biogeosciences, 10, 3109-3125, doi:10.5194/bg-10-3109-2013, 2013.

de Kluijver, A., Soetaert, K., Czerny, J., Schulz, K. G., Boxhammer, T., Riebesell, U., and Middelburg, J. J.: A ${ }^{13} \mathrm{C}$ labelling study on carbon fluxes in Arctic plankton communities under elevated $\mathrm{CO}_{2}$ levels, Biogeosciences, 10, 1425-1440, doi:10.5194/bg-101425-2013, 2013.

Dickson, A. G. and Millero, F. J.: A comparison of the equilibrium constants for the dissociation of carbonic acid in seawater media, Deep-Sea Res., 34, 1733-1743, 1987.

Doney, S. C.: The growing human footprint on coastal and openocean biogeochemistry, Science, 328, 1512-1516, 2010.

Gamble, J. C., Davies, J. M., and Steele, J. H.: Loch Ewe bag experiment, 1974, B. Mar. Sci., 27, 146-175, 1977.

Guieu, C., Dulac, F., Desboeufs, K., Wagener, T., Pulido-Villena, E., Grisoni, J. M., Louis, F., Ridame, C., Blain, S., Brunet, C., Bon Nguyen, E., Tran, S., Labiadh, M., and Dominici, J. M.: Large clean mesocosms and simulated dust deposition: a new methodology to investigate responses of marine oligotrophic ecosystems to atmospheric inputs, Biogeosciences, 7, 2765-2784, 2010.

Hansen, H. P. and Koroleff, F.: Determination of nutrients, in: Methods of seawater analysis, edited by: Grasshoff, K., Kremling, K., and Ehrhardt, M., Wiley-VCH Verlag GmbH, Weinheim, Germany, 159-228, 2007.

Harrison, W. G. and Davies, J. M.: Nitrogen cycling in a marine planktonic food chain: Nitrogen fluxes through principal components and effects of adding copper, Mar. Biol., 43, 299-306, 1977.

Huasheng, H., Laodong, G., and Jingqian, C.: Relationships between particle characteristics and biological activities in controlled ecosystems, in: Proceedings of a symposium held in Beijing: Marine ecosystem enclosure experiments, Beijing, People's Republic of China, 9-14 May 1987, 230-243, 1992.

Jenkins, D., Ferguson, J. F., and Menar, A. B.: Chemical processes for phosphate removal, Water Res., 5, 369-389, 1971.

Jinping, W., Whitney, F. A., Shumin, H., Xiaolin, C., Dongfa, Z., and Shengsan, W.: Introduction to the Xiamen Marine Ecosystem 
Enclosed Experiments, in: Proceedings of a symposium held in Beijing: Marine ecosystem enclosure experiments, Beijing, People's Republic of China, 9-14 May 1987, 158-173, 1992.

John, S. G., Mendez, C. B., Deng, L., Poulos, B., Kauffman, A. K. M., Kern, S., Brum, J., Polz, M. F., Boyle, E. A., and Sullivan, M. B.: A simple and efficient method for concentration of ocean viruses by chemical flocculation, Environ. Microbiol. Rep., 3, 195-202, 2011.

Knuckey, R. M., Brown, M. R., Robert, R., and Frampton, D. M. F.: Production of microalgal concentrates by flocculation and their assessment as aquaculture feeds, Aquacult. Eng., 35, 300-313, 2006.

Lalli, C. M.: Introduction, in: Enclosed experimental marine ecosystems: A review and recommendations: A contribution of the scientific committee on oceanic research working group 85, edited by: Lalli, C. M., Springer US, New York, NY, 1-6, 1990.

McClymont, E. L., Martínez-Garcia, A., and Rosell-Melé, A.: Benefits of freeze-drying sediments for the analysis of total chlorins and alkenone concentrations in marine sediments, Org. Geochem., 38, 1002-1007, 2007.

Mehrbach, C., Culberson, C. H., Hawley, J. E., and Pytkowicx, R. M.: Measurement of the apparent dissociation constants of carbonic acid in seawater at atmospheric pressure, Limnol. Oceangr., 18, 897-907, 1973.

Menzel, D. W. and Case, J.: Concept and design: Controlled ecosystem pollution experiment, B. Mar. Sci., 27, 1-7, 1977.

Niehoff, B., Schmithüsen, T., Knüppel, N., Daase, M., Czerny, J., and Boxhammer, T.: Mesozooplankton community development at elevated $\mathrm{CO}_{2}$ concentrations: results from a mesocosm experiment in an Arctic fjord, Biogeosciences, 10, 1391-1406, doi:10.5194/bg-10-1391-2013, 2013.

Olsen, Y., Andersen, T., Gismervik, I., and Vadstein, O.: Protozoan and metazoan zooplankton-mediated carbon flows in nutrientenriched coastal planktonic communities, Mar. Ecol.-Prog. Ser., 331, 67-83, 2007.

Paul, A. J., Achterberg, E. P., Bach, L. T., Boxhammer, T., Czerny, J., Haunost, M., Schulz, K.-G., Stuhr, A., and Riebesell, U.: No observed effect of ocean acidification on nitrogen biogeochemistry in a summer Baltic Sea plankton community, Biogeosciences Discuss., 12, 17507-17541, doi:10.5194/bgd-1217507-2015, 2015a.

Paul, A. J., Bach, L. T., Schulz, K. G., Boxhammer, T., Czerny, J., Achterberg, E. P., Hellemann, D., Trense, Y., Nausch, M., Sswat, M., and Riebesell, U.: Effect of elevated $\mathrm{CO}_{2}$ on organic matter pools and fluxes in a summer Baltic Sea plankton community, Biogeosciences, 12, 6181-6203, doi:10.5194/bg-12-6181-2015, 2015b.
Pierrot, D., Lewis, E., and Wallace, D.: MS Excel program developed for $\mathrm{CO}_{2}$ system calculations, ORNL/CDIAC-105a, Carbon Dioxide Information Analysis Center, Oak Ridge National Laboratory, US Department of Energy, Oak Ridge, Tennessee, 2006.

Renou, S., Givaudan, J. G., Poulain, S., Dirassouyan, F., and Moulin, P.: Landfill leachate treatment: Review and opportunity, J. Hazard. Mater., 150, 468-493, 2008.

Riebesell, U., Lee, K., and Nejstgaard, J. C.: Pelagic mesocosms, in: Guide to best practices in ocean acidification research and data reporting, edited by: Riebesell, U., Fabry, V. J., Hansson, L., and Gattuso, J.-P., Office for Official Publications of the European Communities, Luxembourg, 95-112, 2011.

Riebesell, U., Czerny, J., von Bröckel, K., Boxhammer, T., Büdenbender, J., Deckelnick, M., Fischer, M., Hoffmann, D., Krug, S. A., Lentz, U., Ludwig, A., Muche, R., and Schulz, K. G.: Technical Note: A mobile sea-going mesocosm system - new opportunities for ocean change research, Biogeosciences, 10, 18351847, doi:10.5194/bg-10-1835-2013, 2013.

Riebesell, U., Bach, L. T., Bellerby, R. G. J., Bermudez Monsalve, R. J., Boxhammer, T., Czerny, J., Larsen, A., Ludwig, A., and Schulz, K. G.: Ocean acidification can impair competitive fitness of a predominant pelagic calcifier, in review, 2016.

Schulz, K. G., Riebesell, U., Bellerby, R. G. J., Biswas, H., Meyerhöfer, M., Müller, M. N., Egge, J. K., Nejstgaard, J. C., Neill, C., Wohlers, J., and Zöllner, E.: Build-up and decline of organic matter during PeECE III, Biogeosciences, 5, 707-718, doi:10.5194/bg-5-707-2008, 2008.

Sukenik, A., Bilanovic, D., and Shelef, G.: Flocculation of microalgae in brackish and sea waters, Biomass, 15, 187-199, 1988.

Svensen, C., Egge, J. K., and Stiansen, J. E.: Can silicate and turbulence regulate the vertical flux of biogenic matter? A mesocosm study, Mar. Ecol.-Prog. Ser., 217, 67-80, 2001.

Vadstein, O., Andersen, T., Reinertsen, H. R., and Olsen, Y.: Carbon, nitrogen and phosphorus resource supply and utilisation for coastal planktonic heterotrophic bacteria in a gradient of nutrient loading, Mar. Ecol.-Prog. Ser., 447, 55-75, 2012.

van Leeuwe, M. A., Villerius, L. A., Roggeveld, J., Visser, R. J. W., and Stefels, J.: An optimized method for automated analysis of algal pigments by HPLC, Mar. Chem., 102, 267-275, 2006.

von Bröckel, K.: Sedimentation of phytoplankton cells within controlled experimental ecosystems following launching, and implications for further enclosure studies, in: Marine mesocosms, edited by: Grice, G. D. and Reeve, M. R., Springer US, New York, NY, 251-259, 1982. 